\title{
Examining Comprehension Strategy Instruction With English Learners' Problem Solving: Study Findings and Educator Preparation Implications
}

Teacher Education and Special Education 2018, Vol. 4I(3) 2I5-228

(C) 2018 Teacher Education Division of the

Council for Exceptional Children

Reprints and permissions:

sagepub.com/journalsPermissions.nav

DOI: 10.1 |77/08884064|8770787

journals.sagepub.com/home/tes

@SAGE

\author{
Michael J. Orosco' and Naheed A. Abdulrahim'
}

\begin{abstract}
Educator preparation in comprehension strategy instruction (CSI) is essential to meeting the needs of English learners (ELs) in contemporary schools. This article provides teacher educators and professional developers with concrete examples of practices to prepare classroom teachers in comprehensive strategy instruction, based on an experimental study that examined the effect (.37) of CSI on third-grade students' $(n=78)$ word-problem-solving (WPS) performance. CSI included problem-solving strategies that (a) helped students to understand the relevant and irrelevant information in a word problem's question; (b) helped students to restate the problem orally, which allowed them to understand, to construct meaning, and to clarify any misunderstanding about the question; and (c) provided instructional feedback with student collaboration for problem solving and solution. Findings indicate that a focus on CSI may help facilitate WPS skills developing for ELs at risk of mathematics-learning difficulties (MLD). Educator preparation recommendations are embedded throughout with implications for future research and practice also discussed.
\end{abstract}

\section{Keywords}

comprehension strategy instruction, English learners, mathematics education, problem solving, mathematics learning disability, teacher professional development and preparation

A large and increasing proportion of students in U.S. schools come from a home in which a language other than English is spoken. About 4.85 million students enrolled in public schools were not yet fully proficient in English in the 2012-2013 school year, representing nearly $10 \%$ of the total public-school student enrollment (National Center for Education Statistics [NCES], 2015). According to The Nation's Report Card (NCES, 2015), the average mathematics score for an English learner (EL) fourth grader was 218 (with $43 \%$ below basic). The challenge for many ELs is not only overcoming a language barrier, but also achieving academically. This poor mathe- matics achievement places many ELs at risk of mathematics-learning difficulties (MLD) and may put them at risk of overidentification for special education (a topic that is beyond the focus of this study). ELs encounter unique mathematics-learning challenges because of the range of instructional needs they require for whom mathematics content in a second

\footnotetext{
'The University of Kansas, Lawrence, USA

Corresponding Author:

Michael J. Orosco, The University of Kansas, Joseph R. Pearson Hall Room 539, I I 22 West Campus Rd., Lawrence, KS 66045, USA.

Email: mjorosco@ku.edu
} 
language is most challenging due to (a) they are increasingly included in general education classrooms where the demands to problem solve and learn from mathematics text are substantial and (b) they are unlikely to receive inadequate mathematics instruction such as lack of exposure to comprehension strategies to improve problem-solving efficiency (e.g., Martiniello, 2008, 2009; National Mathematics Advisory Panel, 2008). ELs benefit from teachers who are prepared in comprehension strategy instruction (CSI) in problem solving so that they can access the general education mathematics curriculum.

Although there is a great deal of professional development (PD) research that supports the value of CSI in reading (e.g., Blachowicz \& Ogle, 2017), much less is understood about how to prepare school professionals to use CSI with ELs in mathematics (e.g., word problems). As an example, although many school personnel (e.g., teachers, paraprofessionals, and tutors) receive PD with CSI in reading and thus building confidence in this area, very few receive preparation with CSI in problem solving and ELs (Orosco \& Abdulrahim, 2017; Kong \& Orosco, 2016; Orosco, 2014a, 2014b; Orosco, Swanson, O'Connor, \& Lussier, 2013; Orosco, 2013). We do not yet know the PD model best suited in preparing teachers to become more responsive to their ELs' problem-solving needs in high poverty schools. The literature reflects a variety of pedagogical perspectives and approaches, often grounded in varying philosophical and theoretical perspectives and resulting in different instructional and educational practices (e.g., Baker, Gersten, \& Lee, 2002; Gersten et al., 2009; Swanson \& Jerman, 2006). We still need to learn which problem-solving components are most effective and how best to prepare school professionals so that they can provide optimal instructional scaffolding to ELs. This is certainly true with respect to implementing complex comprehension strategies with word problems that can be challenging for some teachers to learn.

\section{ELs' Word-Problem Development and Educator Preparation}

ELs are often the poorest in terms of developing word-problem-solving (WPS) skills in English (Orosco \& Abdulrahim, 2017; Kong \& Orosco, 2016; Orosco, 2014a, 2014b; Orosco et al., 2013; Orosco, 2013). These students also demonstrate characteristics of inactive learners who do not monitor their learning or use comprehension strategies effectively. They have not developed the cognitive awareness necessary to assess their understanding as they read word problems and to recognize when their comprehension has broken down in formulating a solution (Bresser, Melanese, \& Sphar, 2009). Preparing school personnel to teach ELs how to use comprehension strategies improves their comprehension. Many of the comprehension strategies associated with the highest effect sizes for students with MLD teach students strategies that prompt them to reflect before, during, and after reading a word problem (e.g., Gersten et al., 2009). These strategies ask students to (a) think about the question that the word problem is asking, (b) find and understand the relevant/irrelevant information in the word problem, and (c) collaborate with other students for accuracy and practicing applying the abovementioned problem-solving skills for solution. It is critical for teachers of ELs with problem-solving challenges to acquire strategies to help them understand word problems because (a) they are increasingly included in general and special education elementary classrooms where the demands to read and learn from mathematics text are substantial and (b) they are unlikely to receive intervention support in mathematics content.

Also, emerging mathematics research with teachers of ELs indicates that instruction in oral language development (e.g., vocabulary skills and math content knowledge) can affect WPS comprehension levels equivalent to native English speakers (Orosco \& Abdulrahim, 2017; Kong \& Orosco, 2016; Orosco, 2014a, 2014b; Orosco et al., 2013; Orosco, 2013). Well-developed English language 
proficiency may be a critical first step to improving WPS skills in ELs. Specifically, providing direct and explicit instruction that (a) provides modeling and oral language development with evidence-based math components, (b) provides questioning support that assists students in understanding and answering word-problem questions, and (c) providing engaging and motivating collaborative practices, which not only get students involved in all mathematics activities but also allow them to practice skills-based instruction by teaching these to one another orally.

In summary, ELs can benefit from teachers prepared with CSI that help them with their problem-solving skills. Thus, the purpose of this study was to solve a critical teacher preparation problem in mathematics. Building on what is already known from related bodies of mathematics research and following state-ofthe-art research procedures, this study developed an educator preparation model applying CSI by tutors for ELs with MLD.

\section{The Challenge}

In spite of the growing problem-solving research on educating students who struggle with word problems, there is surprisingly little research on how teachers provide CSI with word problems in ELs with MLD (Orosco \& Abdulrahim, 2017). One reason may be that we still need to learn for ELs, and in general, what instructional scaffolding models work best for delivering mathematics strategies. Much of the research implemented in this area has focused on English-dominant speaking students (Goldenberg, 2013). Few studies have examined the relation of teaching mathematics strategies to see if they are effective with ELs (Authors, 2016). Research, and associated educator preparation, is needed that identifies and explicates instructional scaffolding practices with mathematics strategies that provide sufficient opportunity for repeated practice with specific feedback and support upon which to improve student WPS achievement (National Mathematics Advisory Panel, 2008). Also, it is important to note that the review of the mathematics strategy litera- ture examined for cultural relevancy found little application of this construct (partly due to the difficulty of interpreting and applying this construct in experimental design) in the problem-solving literature. The authors of this study were aware of this, and because of this, this study's intervention lacked cultural relevancy yet it was important to conduct an experimental study applying CSI to begin to establish a mathematics research foundation on ELs in the United States as it is often recommended for all students.

Although there is a dearth of WPS experiment research on ELs with MLD (e.g., Orosco et al., 2013; Orosco, 2014a, 2014b; Kong \& Orosco, 2016), there is a vast literature on effective evidence-based teaching practices with English-speaking students likely to result in improving mathematics achievement, and WPS development in ELs via teacher preparation. Several recent studies have found support for teaching strategies to improve mathematics achievement, and these instructional scaffolding behaviors can be applied in promoting WPS skills in students with mathematics challenges and learning difficulties. Intervention research has identified core instructional methods effective for students with MLD (Gersten et al., 2009): (a) strategy training with problem representation, (b) modeling with irrelevant and relevant mathematics information, and (c) providing corrective feedback and student verbalization with small group collaboration for problem-solving solution. That is, these intervention studies support explicit instruction that provide (a) instructional strategies designed to create a connection between verbal input and conceptual understanding by creating a mental model (e.g., Kolloffel, Eysink, de Jong, \& Wilhelm, 2009; Xin, Jitendra, \& Deatline-Buchman, 2005), (b) verbal strategies that teach conceptual understanding of irrelevant and relevant concepts and principles of word problems (e.g., Griffin \& Jitendra, 2009; Krawec, Huang, Montague, Kressler, \& de Alba, 2013), and (c) instructional feedback with student collaboration and verbalization with the problemsolving process (e.g., Swanson, Moran, Bocian, Lussier, \& Zheng, 2013; Swanson, Moran, Lussier, \& Fung, 2014). 


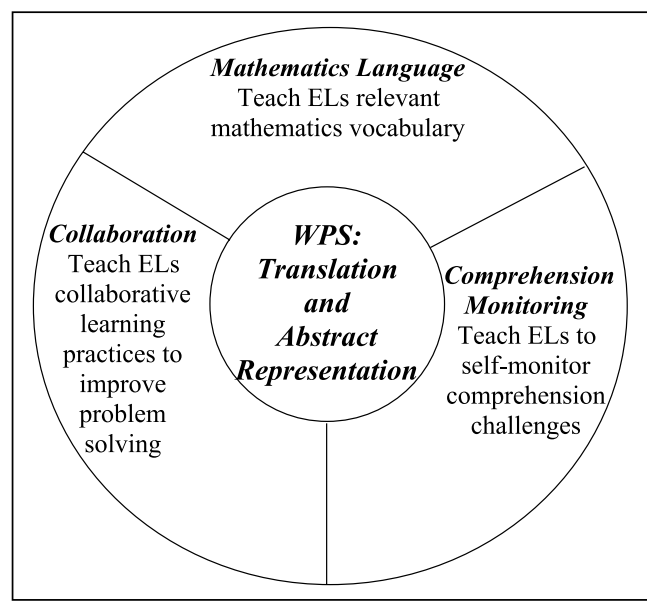

Figure I. WPS conceptual framework. Note. WPS = word-problem solving; EL = English learner.

To examine this topic, a study was completed to investigate the effects of CSI on mathematical WPS achievement via an instructional scaffolding model in third-grade ELs at risk of MLD.

\section{Conceptual Framework}

In considering the importance of the use of the research-based practice provided by direct and explicit instructional scaffolding approaches (e.g., Gersten et al., 2009; Kolloffel et al., 2009; Swanson et al., 2014), EL mathematics research indicates that teachers must be prepared to help ELs take this information and create a problem-solving process as illustrated in Figure 1 (Orosco et al., 2013; Orosco, 2014a, 2014b; Orosco \& Abdulrahim, 2017). As shown, teachers must provide the instructional scaffolding that (a) teaches the language of mathematics (e.g., vocabulary) so that students can contextualize and bring meaning to this language, (b) teaches students to monitor comprehension when WPS challenges arise, and (c) provides collaborative learning practices so that ELs practice their language and problem-solving skills (Kong \& Orosco, 2016; Orosco \& Abdulrahim, 2017). The teaching of WPS in a second language is a complex task that requires integrating WPS theory and instructional pedagogy. Therefore, conceptually, WPS for ELs is represented as a two-part comprehension model (e.g., Kintsch \& Greeno, 1985). Phase one of WPS comprehension involves the translation of printed words into verbal input (e.g., linguistic processing and reading) involving both accuracy and efficiency. Problem translation is the ability to understand the relevant and irrelevant information in a problem, which can also be seen as text comprehension. As an example, as ELs are learning English as a second language, they may need to be taught to restate the problem orally, which helps them understand, construct meaning, and clarify any misunderstanding about the word problem through instructional scaffolding dialogue. The second conceptual phase (i.e., abstract-problem representation) reflects the cognitive processes, mathematics skills, and knowledge involved in understanding the word problem. In this vein, teachers must provide the instructional scaffolding that allows the student to comprehend the wordproblem information and translating this into a written statement for a solution. Finally, WPS via instructional scaffolding can be improved through collaboration with teacher support or collaboration with more capable peers for accuracy and practice applying word-problem strategies for solution. During this time, teachers scaffold ELs how to provide feedback to each other and check for understanding by generating and answering questions about each other's problem-solving process to assigned word problems (Kong \& Orosco, 2016; Orosco \& Abdulrahim, 2017). The conceptual model serves as (a) a foundation for examining ELs' mathematics comprehension skills and (b) core content for educator preparation.

\section{Method}

Seventy-eight third-grade Hispanic EL children (42 boys, 36 girls) at risk of MLD from a west coast state public urban school district participated in this study and were assigned to treatment $(n=48)$ or control $(n=30)$ condition within each classroom. The school district's population consisted of 55\% Hispanic (all Latino ELs), 22\% African American, 
Table I. Pretest Information for Children by Treatment Conditions.

\begin{tabular}{|c|c|c|c|c|c|c|c|c|}
\hline & \multirow{2}{*}{\multicolumn{2}{|c|}{$\begin{array}{c}\text { Treatment group } \\
\text { (Pre) }\end{array}$}} & \multirow{2}{*}{\multicolumn{2}{|c|}{$\begin{array}{c}\begin{array}{c}\text { Control group } \\
(\text { Pre })\end{array} \\
\text { EL }(n=30)\end{array}$}} & \multirow{2}{*}{\multicolumn{2}{|c|}{$\begin{array}{c}\text { Treatment group } \\
\text { (Post) } \\
\text { EL }(n=48)\end{array}$}} & \multirow{2}{*}{\multicolumn{2}{|c|}{$\begin{array}{c}\begin{array}{c}\text { Control group } \\
\text { (Post) }\end{array} \\
\text { EL }(n=30)\end{array}$}} \\
\hline & & & & & & & & \\
\hline & $M$ & $S D$ & $M$ & $S D$ & $M$ & $S D$ & $M$ & $S D$ \\
\hline \multicolumn{9}{|c|}{ Computation } \\
\hline WIAT & 14.98 & 2.79 & |4.7| & 3.68 & 22.29 & 6.41 & 22.50 & 7.05 \\
\hline WRAT & 22.90 & 1.79 & 22.45 & 3.02 & 23.02 & 4.35 & 23.54 & 4.82 \\
\hline \multicolumn{9}{|c|}{ Problem solving } \\
\hline $\mathrm{KM}$ & 2.71 & 1.55 & 2.74 & 1.61 & 4.06 & 2.03 & 4.17 & 2.26 \\
\hline TOMA & 1.69 & 1.17 & 2.04 & 0.92 & 3.84 & 1.90 & 3.46 & 1.50 \\
\hline
\end{tabular}

Note. EL = English learner; WIAT = Wechsler Individual Achievement Test; WRAT = Wide Range Achievement Test; $\mathrm{KM}=$ KeyMath Revised Diagnostic Assessment; TOMA = Test of Mathematical Abilities.

14\% White, 5\% Asian, and 4\% Other. The school district was considered a high-poverty school, as it had approximately $75 \%$ of its population in the free or reduced-price lunch program. The term Latino EL is used because the student population had been identified as coming from Latin American descendants (e.g., Mexican, Mexican American), and they were acquiring English as a second language. The school district's instructional curriculum functioned as English as a second language program. Given that English as a second language instruction was used with the population, this project examined the use of CSI in English. However, though beyond the scope of this project, additional research in bilingual settings would inform effects of CSI use in Spanish. Also, because the school functioned as an English as a second language program, the participant's school district did not disclose native language proficiency scores. The English level of the participants was categorized by their state's english language development test (ELDT) as EL intermediate. The ELDT is a standardized measure of English listening, speaking, reading, and writing with reliability scores between 0.73 and 0.94 across elementary grade levels. According to the ELDT, students at the EL intermediate level begin to tailor their English-language skills to meet communication and learning demands with increasing accuracy. In addition, ELs at this stage of English development are able to identify and understand more concrete details, some major abstract concepts and some details of extended discourse in English. They are able to respond with increasing ease to more varied communication and learning demands with a reduced number of errors. Oral and written production has usually expanded to sentences, paragraphs, and original statements and questions in the English.

\section{Identification of EL at Risk of MLD}

This study followed the general agreement by researchers that it is best to use an absolute definition of MLD (cutoff score on achievement) rather than discrepancy between achievement and IQ (Fletcher et al., 1989; Siegel \& Ryan, 1989). In determining the atrisk criteria for MLD for the chosen intervention sample, this study considered students who (a) had continued to experience WPS challenges and who had not responded well to general mathematics instruction, district, and state mandated tests over a 3-year period; and (b) who had performed below the 25th percentile on a standardized WPS achievement measure (e.g., see Table 1 for a description). In addition, students were considered for the sample if Spanish was spoken as their native language, as determined by the school's home language survey and parent consent. 


\section{Experimental Design}

General education instruction. Classroom observations indicated that general education instruction consisted of homeroom teachers using a direct instructional approach with district standards-based mathematics curriculum. Teachers followed a hierarchical instructional sequence, in which the majority of the instructional time focused on teaching basic skills (e.g., procedural skills) and less time on more complex skills such as explicitly teaching problem-solving skills (e.g., mathematics strategies). General problem-solving steps included the following: (a) understand, (b) plan, (c) carry out the plan, and (d) look back. A number of the components within the general education curriculum were also utilized in this study (e.g., checking each step of the plan, etc.). However, in contrast to general education instruction, this study's intervention directly focused on specific components of CSI over consecutive sessions presented in a predetermined order, which is necessary to support ELs who are struggling with mathematics.

Intervention. This study's treatment model supplemented general education mathematics teaching by providing small-group pullout instruction (three to five students per group) to the intervention group during the school day. Participants were randomly selected and categorized based on teacher recommendation (all students had low mathematics and research scores and a need for intervention), and a list was randomly generated (based on a standardized WPS scores) to assign students to a small group. Word-problem types (e.g., joining problems, separating problems, part-partwhole problems, and comparing problems) followed those used in the general-education curriculum. In this study, each participant received a booklet of 20 lessons consisting of five word problems per lesson from the general education curriculum. These word problems were verbally modified based on a scaffolding ladder with word problems that increasingly became more challenging over the course of the study. That is, in this approach the students were first taught strategies with basic word problems. As students became proficient in general problem-solving strategies and solved basic word problems correctly (e.g., 100\% WPS accuracy), the intervention introduced more challenging word problems, which required further CSI. If not, the students were given more practice at the current level until $100 \%$ mastery was achieved. Because the intervention was administered in a small group, students were not moved up to the next level immediately to allow for student pairing. Fidelity checks ( $20 \%$ of lessons implemented) were conducted by trained graduate and undergraduate students to ensure that the students were using comprehension strategies proficiently in their notebooks. The observer coded for fidelity and scored observed or did not observe for each strategy observed in student's notebooks. A total agreement calculation method indicated the stable presence of strategy behaviors for each lesson (97\%). If fidelity of implementation fell below $80 \%$, additional instructional scaffolding was provided to the students. Students in the treatment condition received intervention by trained tutors for 30 minutes twice a week for a period of 10 weeks, for a total of 20 lessons. Students in the control condition received 50 minutes of daily general-education mathematics direct instruction only and were not responding well to this instruction. CSI was selected as the intervention because it has been built on a foundation of direct explicit instructional scaffolding and associated with effective teaching such as collaborative group work, interactive dialogue, and procedural strategies.

Intervention procedure. In this study, trained undergraduate and graduate tutors with a background in education (e.g., elementary and special education majors) followed scripted comprehension strategies (see instructional scaffolding that follows below) with WPS practice that lasted for 30 minutes per session. Tutors participated in a 4-hour training session to become familiar with intervention materials and instructional techniques. The participants needed to see concrete examples of how mathematics strategies were related to ELs. The tutors were taught not only how to implement 
mathematics strategies, but also why, so that they could develop an understanding of the underlying conceptual rationale for each of the strategies and collaborative-based teaching components that made up this PD. Prior to implementation of interventions with students, tutors practiced delivering small group lessons to other tutors receiving feedback. Tutors were provided with scripted lessons (see the appendix for an example of lesson dialogue) and student booklets for implementation of lessons. In addition, tutors met with researchers to receive feedback on lesson implementation, review future lessons, and address any studentlearning issues. The students discussed each strategy and if they demonstrated $100 \%$ mastery (via verbal discussion), the tutor proceeded to the next treatment. Students were provided multiple opportunities to practice the strategy to demonstrate mastery. If students did not comprehend a strategy, the tutor provided explicit instruction until students understood before providing the next strategy. Instructional scaffolding was as follows.

Restatement of the question: First, the tutor read the word problem aloud and modeled for them finding the question and understanding what the question was about. Next, students were asked to restate the question and to think about (i.e., develop a mental visualization model) through verbalization to the teacher what the question was asking. Restating of the question allowed students to help them understand, to construct meaning, and to clarify any misunderstanding about the question. (Students wrote down the question in a full sentence in their notebook.)

Relevant information: Next, the tutor taught students how to find and understand relevant information (e.g., numbers and vocabulary) that was needed to comprehend and solve the word problem. By finding relevant information related to word problems, students were taught to activate background knowledge (i.e., relating what was in the word problem to other problems they may have practiced). (Students wrote down relevant information in their notebook.)
Irrelevant information: Also, the tutor showed students how to find and understand irrelevant information (e.g., sentences) that was not needed to solve the word problem. This step allowed students to determine the importance of the information they were reading and analyze nonessential information. (Students wrote down irrelevant information in their notebook.)

Collaboration for solution: Finally, students spent time collaborating (in pairs) for accuracy and practicing applying the aforementioned steps to word problems for solution. During this time, the tutor provided feedback and checked for understanding by generating and answering questions about students' problem-solving process to assigned word problems.

Independent practice: The independent practice phase of the lesson directed students to solve three word problems, similar in difficulty to the previously modeled and guided practice word problems. Students were directed to read the problems independently, and list word-problem situations based on the strategies and to solve the problems "just like we did" during the lesson. The time allocation for independent practice phase was 15 minutes. The participant's workbooks were assessed each session to determine strategy implementation (restatement, relevant information, irrelevant information, and understanding). A CSI composite score was created from the average of the strategies used.

\section{Pre- and Posttest Measures}

Calculation accuracy. Calculation accuracy (i.e., basic mathematics skills) was assessed at both pretest and posttest. Calculation skills have been found to have a direct effect on WPS (Swanson, Jerman, \& Zheng, 2008). The arithmetic computation subtest for the Wide Range Achievement Test-Third Edition (WRAT; Wilkinson, 1993) and the numerical operations subtest for the Wechsler Individual Achievement Test (WIAT; Psychological Corporation, 1992b) were administered to 
Table 2. Hierarchical Linear Models Predicting Posttest PSA.

\begin{tabular}{|c|c|c|c|c|c|c|}
\hline \multirow[b]{2}{*}{ Fixed effects } & \multicolumn{2}{|c|}{ Unconditional model } & \multicolumn{2}{|c|}{ Model I } & \multicolumn{2}{|c|}{ Model 2} \\
\hline & Estimate & SE & Estimate & $S E$ & Estimate & $S E$ \\
\hline Intercept & 0.08 & 0.15 & 0.07 & 0.14 & 0.11 & 0.15 \\
\hline $\mathrm{CSI}$ & & & $0.46^{*}$ & 0.20 & $0.37 *$ & 0.16 \\
\hline \multicolumn{7}{|l|}{ Covariates } \\
\hline $\mathrm{RC}$ & & & & & $0.13^{* *}$ & 0.04 \\
\hline Pretest & & & & & $0.45 * * *$ & 0.09 \\
\hline Random Effects & Variance & $S E$ & Variance & $S E$ & Variance & $S E$ \\
\hline Teacher & 0.10 & 0.13 & 0.08 & 0.12 & 0.15 & 0.12 \\
\hline Residual & $0.68 * * *$ & 0.12 & $0.59 * * *$ & 0.13 & $0.28 * * *$ & 0.06 \\
\hline \multicolumn{7}{|l|}{ Fit Statistics } \\
\hline Deviance & \multicolumn{2}{|c|}{186.4} & \multicolumn{2}{|c|}{137.2} & \multicolumn{2}{|l|}{98.6} \\
\hline AIC & \multicolumn{2}{|c|}{190.4} & \multicolumn{2}{|c|}{145.2} & \multicolumn{2}{|l|}{110.6} \\
\hline $\mathrm{BIC}$ & \multicolumn{2}{|c|}{190.6} & \multicolumn{2}{|c|}{146.0} & \multicolumn{2}{|l|}{112.3} \\
\hline
\end{tabular}

Note. PSA = problem-solving accuracy (composite score of word-problem solving, KeyMath and TOMA); CSI = comprehension strategy instruction composite score; $\mathrm{RC}=$ reading comprehension; Pretest = composite score of word-problem solving (KeyMath and TOMA); AIC = Akaike's information criterion; $\mathrm{BIC}=$ Bayesian information criterion; KM = KeyMath Revised Diagnostic Assessment; TOMA = Test of Mathematical Abilities. $*_{p}<.05 . * * p<.01$. ***p $<.001$.

measure calculation ability. Two forms of the tests were counterbalanced across participants at pretest and posttest. The subtests required written computation to problems that increased difficulty. The dependent measure was the number of problems correct, which yielded a standard score $(M=100, S D=15)$.

Word-problem accuracy. Two measures were individually administered to assess pre- and posttest problem solving ability: (a) the problem-solving subtests from the Test of Mathematical Abilities (TOMA; Brown, Cronin, \& McIntire, 1994) and the KeyMath Revised Diagnostic Assessment (KM; Connolly, 1998). A composite score based on the summation of the two subtests' means was created as the outcome measure of problem-solving ability.

Reading comprehension. Reading comprehension (RC) was assessed by the Passage Comprehension subtest from the Test of Reading Comprehension-Third Edition (TORC; Brown, Hammill, \& Weiderholt, 1995).

Statistical analysis. Multilevel regression analysis (with pretest and RC as covariates) was used in this study to analyze treatment effects to help equate intact groups and is useful in reducing systematic bias and error variance (Bryk \& Raudenbush, 2002). The fixed- and randomeffect parameter estimates were obtained using PROC MIXED in SAS 9.3 (SAS Institute, 2010). A full maximum likelihood (ML) estimation was used to compute the parameters at posttest because of some attrition in sample size. Despite unequal sample sizes, the assumption of equal covariance matrices was met in all analyses. The homogeneity of regression slopes assumption was examined by testing the covariate by intervention interaction effect, and it was met in all analyses. The convergence criterion was found to be satisfied. The criterion variables in the regression analysis were grand mean centered (Singer \& Willett, 2003) posttest scores for problem-solving accuracy.

\section{Results}

Table 1 presents the descriptive data of students at pretest by treatment groups, and Table 2 presents the correlation data for intervention group. No significant difference was found in terms of gender status between the 
treatment and control condition, $\chi^{2}(1, n=77)$ $=0.11, p>.05$. The composite scores for WPS accuracy were based on the mean $z$ score computed for all three assessments (KM and TOMA).

\section{Pretest Comparisons}

A MANOVA was computed among the control and treatment groups on composite pretest mean $z$ scores for WPS accuracy assessments (KM and TOMA). The MANOVA was significant showing a WPS advantage for students in the control condition relative to student in treatment condition, Wilks's Lambda $=.91$, $F(1,77)=5.29, p<.01$. A univariate test was computed on the composite pretest mean $z$ scores for WPS measures. The univariate test also favored students in the control condition when compared with treatment conditions on the measures of problem-solving accuracy, (1, $77)=2.81, p<.01, \eta 2=.09, p<.01$. The post hoc comparison (Tukey test) indicated that pretest differences among the control and treatment conditions were significant $(p<.05)$ on problem-solving components.

\section{Intervention Outcomes on Standardized Measures}

The design of this study allowed for the determination whether the level of posttest problem-solving performance achieved by participants in the intervention was statistically comparable with posttest performance in students in the control condition (Table 2).

Unconditional model. As shown on the left side of Table 2 for the unconditional model the random effect for the intercept between classrooms was significant, yielding an intraclass correlation of $.15(.10 / .68)$. The fixed effects provided an estimate of the average intercept for the total sample. The average posttest problem-solving accuracy $z$ score for Grade 3 children without CSI treatment was 0.08 .

Conditional Model I. Table 2 shows the first conditional model (Conditional Model 1) entered with treatment condition CSI without controlling for pretest or RC. Overall, the model indicated that the mean wave problemsolving $z$ score for the participants was 0.07 . Posttest problem-solving accuracy score was 0.46 for CSI condition. This result indicated a significant posttest score when students received CSI. The model also reduced the significant random effects related to intercepts between classrooms when compared with the unconditional means model and accounted for $20 \%$ of the explainable variance $(0.10-.08 /$ $0.10)$. No significant advantage emerged at posttest for students receiving general mathematics instruction. The deviance score was lower than the unconditional model, as was Akaike's information criterion (AIC) is conservative for the number of parameters estimated), suggesting that Conditional Model 1 was a good fit to the data.

Conditional model 2. The final conditional model sought to determine whether entering covariates (e.g., RC and pretest scores) improved the model fit. The results indicated a significant posttest score advantage for students receiving CSI treatment. Posttest problem-solving accuracy score was 0.37 for the CSI condition when controlling for student $\mathrm{RC}$ and pretest mathematics scores. The model also reduced the random effects related to intercepts between classrooms when compared with unconditional means model. This model yielded the lowest deviance (98.6) and AIC (110.6) values when compared with other models, indicating a better fit. No significant advantage emerged at posttest for students in control condition.

Effect size. Finally, because this was a smallscale study, effect size was computed for treatment condition applying Hedges $g$ (Hedges, 1981) and indicated a significant treatment effect for the CSI (.37) condition.

\section{Discussion-Implications for Educator Preparation}

This study investigated whether CSI within word problems facilitated posttest problemsolving accuracy. Overall, the findings 
indicated that CSI that focused on directly and explicitly: (a) modeling reading and having students restate the word problem, (b) identifying irrelevant information, (c) identifying relevant information (e.g., question, vocabulary, and numbers), and (d) collaborating for problem solution facilitated posttest solution accuracy performance when compared with the control condition that included ELs with similar qualities. The results will now be discussed in terms of the research question that directed the study.

Research Question 1: Do strategies focused on comprehension within word problems facilitate solution accuracy for ELs at risk of MLD?

The results indicated a small but significant effect at posttest for CSI (.37) when compared with control condition. For the treatment condition, one of the reasons for this significance maybe that CSI helps student's link relevant mathematics information more efficiently to prior knowledge by providing a model in which problems solving serves primarily to interpret the word problem. That is, CSI helps students make connections, ask questions, visualize, infer and predict, synthesize, and monitor their thinking about word problems. Finally, applying CSI allows for the integration of reading, language, and mathematics cognition that can help students to think effectively and understand ideas through reading and language and apply these skills toward solving word problems. Overall, the findings indicated that CSI may be an effective way to improving WPS performance among students at risk of MLD.

\section{Implications}

The implications from this study are clear that institutes of higher education (IHE) faculty need to provide future and current teachers with explicit research-based practices that have been validated with ELs. This would give preservice teachers a good start to feeling comfortable with providing this type of instruction to ELs. Educator preparation recommendations are as follows.

Recommendation 1: IHE faculty should provide an instructional segue with evidence-based practices to show teachers on how to match explicit skills-based instruction, such as the one researched through this study, with EL pedagogy.

Recommendation 2: IHE faculty should prepare teachers of ELs with problem-solving skills built on a platform of explicit teaching (e.g., integrating interactive teaching dialogue), and making sure teachers understand the second language acquisition process and how it relates to problem solving in ELs. The problem-solving skills should include direct and explicit instruction in (a) reading word problems aloud and modeling for them, finding the question, and understanding the question; (b) asking students to restate the question and to think about (i.e., develop a mental visualization model) through verbalization to the teacher what the question was asking; (c) finding and understanding relevant (e.g., numbers and vocabulary) and irrelevant information (e.g., nonessential sentences), that is, needed to comprehend and solve the word problem; and (d) finally, allowing students to spend time collaborating (in pairs) for accuracy and practicing applying the aforementioned steps to word problems for solution. During this time, the teacher provides feedback and checks for understanding by generating and answering questions about students' problem-solving process of word problems.

Recommendation 3: IHE faculty should provide PD that helps teachers develop skills in developing and understanding instructional drawn inferences that allow them to determine whether their problemsolving teaching is being successful or not with ELs. Evidence of success might include providing teachers with PD in which they see mathematics strategies modeled and given opportunities for extensive hands-on practice of these strategies. That is, teachers need to be taught not only how to implement 
mathematics strategies, but also why they are implementing them, so that they have an understanding of the underlying conceptual rationale for each of the strategies and collaborative-based teaching components that make up this CSI. This PD would allow them to change their patterns of practice over time and help them make the necessary adjustments to successfully teach problem-solving skills to ELs.

Recommendation 4: IHE faculty should provide educator preparation for instructing ELs in mathematics should incorporate English language development best practices, such as those included in this study, with strategy instruction to provide sufficient opportunities to master problemsolving abilities.

Recommendation 5: IHE faculty should provide educator preparation in developing teaching approaches that integrate students' background knowledge. From this perspective, teachers should be shown to go beyond "just plain good teaching" that omits ELs' background experiences, in which they make the concentrated effort to incorporate students' experiences in their mathematics instruction to engage students' in authentic student-centered mathematics learning.

Recommendation 6: IHE faculty should provide educator preparation that teaches mathematics comprehension is more than solely teaching core mathematics skills, but that developing mathematics comprehension involves a dynamic interdisciplinary process that requires not only direct explicit instruction in evidencebased mathematics skills but at times also involves integrating reading (e.g., phonological awareness, phonics, vocabulary, comprehension, and oral language) and writing elements matched with student background knowledge with peer-learning opportunities, cooperative learning, and gradual release of responsibility models in a mathematics language-rich environment.

\section{Limitations}

Although the findings of this study demonstrated a small but significant effect of CSI (.37) on ELs' WPS accuracy, there were limitations to this study. First this was a smallscale experiment, and data were collected on a small sample $(n=78)$ across a total of 20 lessons (10 weeks), and because of this, generalizing intervention effectiveness to other EL populations is limited at this time. Next, ELs were provided small group instruction by highly skilled and well-trained tutors; however, caution must be noted to the extent that strategies to improve students' problem-solving accuracy with teachers who have less training and provide instruction in general education classrooms with a larger number of students have not been tested. This limitation highlights need for effective educator preparation in this content area as summarized above.

\section{Summary}

The findings from this study support the use of comprehension strategies for improving WPS performance in ELs at risk of MLD and indicate needed teacher education training. In particular, educator preparation should focus on relevant language and strategies to provide collaborative support to significantly improve WPS solution.

\section{Appendix}

\section{Lesson Plan Example}

Word problem. Esmeralda was shopping at the mall. She visited four different stores. She bought a new pair of shoes and a new purse. She spent a total of US $\$ 45$. The purse cost US\$10. How much money did Esmeralda spend on a new pair of shoes?

Restatement of the question. Teacher reads aloud the word problem and models for them finding and understanding the question. A word problem asks a question: How much money did Esmeralda spend on the new pair of 
shoes? Okay, let us restate the question out loud. (Teacher/Students read the question aloud). Now, let us talk about this question and think about what it is asking. First, we need to understand what how much money and spend means. We all understand the concept of money (holding up a dollar bill) and a new pair of shoes (pointing to her shoes) but do we understand what how much and spend means in this question. In this question, how much means what amount or price Esmeralda spends on a new pair of shows. Spend means to buy. We are going to need to find information in our word problem to answer this question.

Relevant information. Teacher finds and teaches an understanding of relevant information. Before we can solve this word problem, we need to think about what we already know. In each word problem, we need to find important information. This information may include numbers or mathematics words. This is called relevant information. The word relevant means important information to solve the problem. Please read these sentences with me. (Teacher/Students read sentences aloud). In this word problem, the relevant information is She bought a new pair of shoes and a new purse. She spent a total of US\$45. The purse cost US\$10. Remember, relevant means important information to answer the question. For this problem, our relevant sentences were as follows: She bought a new pair of shoes and a new purse. She spent a total of US\$45. The purse cost US\$10. Now, let us go back to our question: How much money did Esmeralda spend on a new pair of shoes? Our relevant or important information can help us answer this question. We know that Esmeralda spent a total of US\$45 and the purse cost US\$10. But we do not know what the pair of shoes cost, this is what we will need to think about.

Irrelevant information. Teacher finds and teaches an understanding of irrelevant information. Okay, before we try to solve the problem, we also need to think about the other information in the word problem to see if we need it for problem solving. Sometimes word problems have information that we do NOT need. This is called irrelevant information. The word irrelevant means information that is NOT important to solve the problem. Please read this sentence with me. In this word problem, the irrelevant information is She visited four different stores. Why is this information irrelevant? Now, let us go back to our question: How much money did Esmeralda spend on a new pair of shoes? Does this question ask us about Esmeralda visiting other stores? If you said no, you are correct. This is why the sentence: She visited four different stores is irrelevant to solving this word problem as it gives no information that we need to answer the question: How much money did Esmeralda spend on a new pair of shoes?

Collaboration for solution. Teacher collaborates with students for a solution. So now that we understand what the problem is about, we can set up our equation and solve together. A mathematics equation is the same thing as a mathematics number sentence. An equation says that two things are the same. We use the equal sign (writes an equal sign on the board) to show that both sides of the equal sign are the same. We set up our equation to solve for the answer. Can someone repeat the question? In this word problem, we know that the question is asking: How much money did Esmeralda spend on a new pair of shoes? In this word problem, we looked for information and found that the relevant information was She bought a new pair of shoes and a new purse. She spent a total of US\$45. The purse cost US\$10. Okay, now, let us put this information together for a solution. We know that how much means what amount or price Esmeralda spends on a new pair of shows. We can use this information to set up the problem to answer our question. The question was How much money did Esmeralda spend on a new pair of shoes? We know that Esmeralda bought a purse for US\$10 and spent a total of US\$45. First, if I write an equation, I can write the following: shoes + purse $=$ $\$ 45.00$. Next, I can write in the price of the purse in this equation: shoes $+\$ 10.00=$ $\$ 45.00$. Finally, I need to find out the price of the shoes, I can write my equation like 
this: shoes $=\$ 45.00-\$ 10.00$. Esmeralda shoes cost her US\$35.00.

\section{Declaration of Conflicting Interests}

The author(s) declared no potential conflicts of interest with respect to the research, authorship, and/or publication of this article.

\section{Funding}

The author(s) received no financial support for the research, authorship, and/or publication of this article.

\section{References}

Baker, S., Gersten, R., \& Lee, D. S. (2002). A synthesis of empirical research on teaching mathematics to low-achieving students. The Elementary School Journal, 103, 51-73.

Blachowicz, C., \& Ogle, D. (2017). Reading comprehension: Strategies for independent learners. Guilford Publications.

Bresser, R., Melanese, K., \& Sphar, C. (2009). Supporting English language learners in math class, Grades 3-5. Sausalito, CA: Math Solutions.

Brown, V. L., Cronin, M. E., \& McIntire, E. (1994). Test of mathematical ability. Austin, TX: PRO-ED.

Brown, V. L., Hammill, D., \& Weiderholt, L. (1995). Test of reading comprehension. Austin, TX: PRO-ED.

Bryk, A. S., \& Raudenbush, S. W. (2002). Hierarchical linear models: Applications and data analysis methods. London, England: Sage.

Connolly, A. J. (1998). KeyMath revised/normative update. Circle Pines, MN: American Guidance Services.

Fletcher, J. M., Epsy, K. A., Francis, P. J., Davidson, K. C., Rourke, B. P., \& Shaywitz, S. E. (1989). Comparison of cutoff and regression-based definitions of reading disabilities. Journal of Learning Disabilities, 22, 334-338. doi:10.1177/002221948902200603

Fuchs, L. S., Fuchs, D., Compton, D. L., Hamlett, C. L., \& Wang, A. Y. (2015). Is word-problem solving a form of text comprehension? Scientific Studies of Reading, 19, 204-223. doi: 10.1080/10888438.2015.1005745

Gersten, R., Chard, D. J., Jayanthi, M., Baker, S. K., Morphy, P., \& Flojo, J. (2009). Mathematics instruction for students with learning disabilities:
A meta-analysis of instructional components. Review of Educational Research, 79, 1202-1242. doi:10.3102/0034654309334431

Goldenberg, C. (2013). Unlocking the research on English learners. American Educator, 37(2), 4-39.

Griffin, C., \& Jitendra, A. (2009). Word problemsolving instruction in inclusive third-grade mathematics classrooms. Journal of Educational Research, 102, 187-201. doi:10.3200/ JOER.102.3.187-202

Hedges, L. V. (1981). Distribution theory for Glass's estimator of effect size and related estimators. Journal of Educational Statistics, 6, 107-128. doi:10.2307/1164588

Kintsch, W., \& Greeno, J. G. (1985). Understanding and solving word arithmetic problems. Psychological Review, 92, 109-129. doi:10.1037/0033-295X.92.1.109

Kolloffel, B., Eysink, T. H., de Jong, T., \& Wilhelm, P. (2009). The effects of representational format on learning combinatorics from an interactive computer simulation. Instructional Science, 37, 503-517. doi:10.1007/s11251-008-9056-7

Kong, J. E., \& Orosco, M. J. (2016). Word problem solving strategy for minority students at risk for math difficulties. Learning Disability Quarterly, 39(3), 171-181

Krawec, J., Huang, J., Montague, M., Kressler, B., \& de Alba, A. M. (2013). The effects of cognitive strategy instruction on knowledge of math problem-solving processes of middle school students with learning disabilities. Learning Disability Quarterly, 36, 80-92. doi:10.1177/0731948712463368

Martiniello, M. (2008). Language and the performance of English-language learners in math word problems. Harvard Educational Review, 78, 333-368.

Martiniello, M. (2009). Linguistic complexity, schematic representations, and differential item functioning for English language learners in math tests. Educational Assessment, 14, 160-179.

National Center for Education Statistics. (2015). The nation's report card: Mathematics 2015. Washington, DC: Institute of Education Sciences, U.S. Department of Education.

National Mathematics Advisory Panel. (2008). Foundations for success: The final report of the National Mathematics Advisory Panel. Washington, DC: U.S. Department of Education.

Orosco, M. J., Swanson, H. L., O'Connor, R. E., \& Lussier, C. (2013a). The effects of dynamic strategic math on English language learners' 
word problem solving. Journal of Special Education, 47(2), 96-107.

Orosco, M. J. (2013b). The development of a math comprehension strategy in Spanish for Latino English language learners at risk for math disabilities. International Journal for Research in Learning Disabilities, 1(2), 86-108.

Orosco, M. J. (2014a). A Math Intervention for 3rd. Grade Latino English language learners at Risk for Math Disabilities. Exceptionality, 22(4), 205-225.

Orosco, M. J. (2014b). A word problem strategy for Latino English language learners at risk for math disabilities. Learning Disability Quarterly, 37(1), 45-53.

Orosco, M. J., \& Abdulrahim, N. A. (2017). Culturally responsive professional development for one special education teacher of Latino English language learners with math learning disabilities. Insights on Learning Disabilities: From Prevailing Theories to Validated Practices, 14(1), 73-95.

Psychological Corporation. (1992a). Stanford Diagnostic Mathematics Test. San Antonio, TX: Harcourt Brace.

Psychological Corporation. (1992b). Wechsler Individual Achievement Test. San Antonio, TX: Harcourt Brace.

SAS Institute. (2010). SAS/STAT user's guide. Cary, NC: Author.

Siegel,L. S., \& Ryan,E. B. (1989). The development of working memory in normally achieving and subtypes of learning disabled. Child Development, 60, 973-980. doi:10.2307/1131037

Singer, J. D., \& Willett, J. B. (2003). Applied longitudinal data analysis: Modeling change and event occurrence. New York: Oxford University Press.

Swanson, H. L., \& Jerman, O. (2006). Math disabilities: A selective meta-analysis of the literature. Review of Educational Research, 76, 249-274.

Swanson, H. L., Jerman, O., \& Zheng, X. (2008). Growth in working memory and mathematical problem solving in children at risk and not at risk for serious math difficulties. Journal of Educational Psychology, 100, 343-379. doi:10.1037/0022-0663.100.2.343

Swanson, H. L., Moran, A., Lussier, C., \& Fung, W. (2014). The effect of explicit and direct generative strategy training and working memory on word problem-solving accuracy in children at risk for math difficulties. Learning Disability Quarterly, 37, 111-123.

Swanson, H. L., Moran, A. S., Bocian, K., Lussier, C., \& Zheng, X. (2013). Generative strategies, working memory, and word problem solving accuracy in children at risk for math disabilities. Learning Disability Quarterly, 36, 203-214. doi:10.1177/ 0731948712464034

Wilkinson, G. S. (1993). The wide range achievement test. Wilmington, DE: Wide Range.

Xin, P. Y., Jitendra, A. K., \& Deatline-Buchman, A. (2005). Effects of mathematical word problem solving instruction on students with learning problems. Journal of Special Education, 39, 181-192. doi:10.1177/00224669050390030501

\section{Author Biographies}

Michael J. Orosco is an associate professor in education specializing in bilingual special education at the University of Kansas. His interdisciplinary research includes developing a theoretical model of learning disabilities for English Learners (ELs) that includes the sociocognitive mechanisms that moderate mathematical and reading performance. $\mathrm{He}$ was a bilingual special education teacher in Colorado for five years before earning a $\mathrm{PhD}$ in Education from the University of Colorado at Boulder.

Naheed A. Abdulrahim is a doctoral student in special education at the University of Kansas. Her program of research focuses on literacy-based instructional interventions for English language learners (ELLs) with learning disabilities (LD). She has over thirteen years of teaching experience with school-age children and adult learners with and without disabilities. 